\title{
THE ROLE OF CONFERENCES AND REFEREED JOURNALS IN AUSTRALIAN INFORMATION SYSTEMS RESEARCH ${ }^{15}$
}

\author{
Gail Ridley \\ Department of Information Systems \\ University of Tasmania \\ GPO Box 252-87 Hobart Tasmania 7001 \\ Email: Gail.Ridley@infosys.utas.edu.au
}

\begin{abstract}
The premise of this paper is the need for the IS discipline in Australia to identify its nature and traditions before promulgating both to gain greater access to political power and resources. The survey results reported help characterise Australian IS research by assessing the significance of conference publications and determining which international and national conferences and refereed journals are perceived by leading IS researchers to be the most appropriate and of the highest quality as publication outlets. Comparison is made between the results of this study and North American rankings. Results from the study support the claim that refereed conference publications are significant to IS researchers and help legitimise this style of publication.
\end{abstract}

\section{INTRODUCTION}

Information Systems (IS) is an emerging field. Over the last decade there has been an explosion in research undertaken in the area. The number of new IS journals and recently introduced university IS research programmes provide evidence of this claim (Galliers 1992).

However, as Australian IS research education has a short history and current researchers come from disparate employment and educational backgrounds, researchers bring different interests and approaches to Australian IS research (Shanks, Rouse \& Arnott 1993) which influence the content and style of research undertaken. Partly too because reference disciplines play a significant role in IS, its boundaries are not well established. As a result of these factors and others, little IS tradition or orthodoxy have been established and recognised in Australia.

As the IS discipline is not certain of its own nature and lacks social standing, it has a limited ability to lobby and exert political influence (King 1993). One result has been a limited representation on relevant decision making bodies that control access to resources, power and status, and a dependence on the decisions of researchers from other disciplines. For example, initially there was no IS representative included in the Working Party to undertake a study to develop a Discipline Research Strategy for Information Technology in Australia (Arnott 1996). As IS gives little guidance on appropriate bases for making determinations, the author considers that de facto decisions are made, often based on the traditions laid down in the disciplines of the decision makers. Because IS research is unlikely to score well on measures established for other disciplines, the consequences are likely to be negative. For example, even though only three of the sixteen subcategories from the 'Information, Computers and Communication Technologies' section of the 1995 Australian Research Council (ARC) Initial Awards of Large Grants appear to cater for IS research, only one of eight grants awarded within the three subcategories was awarded to a researcher generally acknowledged as belonging to the IS research community (ARC 1995).

Despite IS's applied nature there is an urgent need to assess the character and traditions of IS research and then develop and proclaim explicit guidelines to assist in the recognition of quality research (King 1993). The first Australian attempts to do so and form potential lobby groups are now apparent, for example the Australasian IS Survey 1995 (Keen 1995), the IS Heads of Discipline Meeting at the Australasian Conference on IS 1995 and 1996 and the IS Curriculum Working Conference 1996. However, the author considers that Australian IS research lacks both an awareness of a need for a political identity and background analyses of its nature that will allow the discipline to present a cohesive front. Both issues have been addressed by the Computer Science community in Australia since 1981 with the formation of the Australian Association of Professors of Computer Science as a lobby group, and the collection and publishing of relevant statistics (Bennett et al. 1994). The research described in this paper partly addresses this need in IS.

It has been claimed that for the communication of research results in computing, refereed conference papers are more important than refereed journal papers (Lowe 1995). Without empirical evidence that compares the significance of the two publication forums like that presented in this paper, it may be difficult to convince

${ }^{15}$ A previous version of this paper was presented at the 7th Australasian Conference on Information Systems and appeared in the proceedings of that conference. 
academics from other disciplines of this, for example when they are involved in the appointment of an IS academic or consider an IS research project for an ARC grant. Similarly, the ranking of appropriate journals by quality for Australian IS researchers in this paper will assist those from both within and outside the discipline to make better informed decisions that may affect the future of IS researchers.

Rankings of IS journals and conferences in the literature have been developed by North American researchers and deal with North American journals. There has been a call for analyses that rate journals from both North America and elsewhere (Morrison \& George 1995). It is not known how appropriate North American rankings are for Australian researchers and how non-North American journals or conferences rank against those from North America. If Australian IS researchers are making de facto use of North American rankings of publication outlets, there is a need to learn whether the rankings are relevant.

The research reported describes the first phase of a larger study to investigate the nature and development of IS research in Australian universities. A preliminary stage is to determine the most highly ranked journals and conferences for Australian IS researchers. Establishing a ranked list of appropriate quality publications and an empirical assessment of the significance of conference publications are considered significant enough tasks to be reported independently. It is understood that neither has been done before. As publication acts as a 'legitimator of academic performance' (King 1993) it is critical for IS that its publication patterns be validated. It is remarkable that the importance of conference publications appears not to have been compared to that of journals in an empirical study before, despite its obvious value to the advancement of IS research throughout the world.

\section{BACKGROUND}

\section{Overview of Literature}

A review of literature was conducted where the ranking of literature relevant to IS research had been established or employed.

Some research ranks publications using empirical investigation while other research assumes the leading publication outlets for the field. Although investigation that establishes the ranking of publication outlets based on empirical work (Doke \& Luke 1987; Koong \& Weistroffer 1989; Gillenson \& Stutz 1991; Hamilton \& Ives 1983; Holsapple et al. 1993; Omar \& Goodwin 1991; Vogel \& Wetherbe 1984; Walstrom et al. 1995) is of more relevance than studies that adopt leading journals for further investigation the latter group reveals expert perceptions of the significance of IS journals and conferences and reinforces the standing of journals and conferences. Nord and Nord (1995) combined both approaches in their study which determined top-ranked journals from an examination of the results of three previous investigations, and then grouped them into two tiers.

The four studies, Gillenson and Stutz (1991), Holsapple et al. (1993), Nord and Nord (1995) and Walstrom et al. (1995) provide the most meaningful comparison as they are recent and consider journal rankings by, or for Management Information Systems (MIS or IS) academics. Other recent empirical studies examine subsets of MIS research (Doke \& Luke 1987; Omar \& Goodwin 1991) or address practitioner perceptions (Tsai et al. 1991). This study restricts itself to IS university researcher perceptions as the outcomes are designed to serve that group.

\section{Methodology of Previous Studies}

Some studies have ranked publication outlets using a citation analysis methodology rather than relying on expert perception (Hamilton \& Ives 1982; Holsapple et al. 1993; Omar \& Goodwin 1991; Vogel \& Wetherbe 1984). Holsapple et al. claim that citation analysis is a less subjective technique to rank publication outlets. However, as the quantity of Australian research published in international journals is unknown and publication may be limited to particular outlets, such an approach for this study may unnecessarily limit the publications ranked.

Use of expert perception to represent the quality of journals is an established practice in strategic management, behavioural management and MIS (Walstrom et al. 1995). By expert perception it is meant people who work as professionals in the area. Gillenson and Stutz (1991) polled chairmen and senior IS researchers to rank IS journals.

In the Gillenson and Stutz study and possibly the Walstrom et al. (1995) study, 'not familiar' responses to journals have been ignored rather than treated as a zero. As Holsapple et al. (1993) and Nord and Nord (1995) use criterion based filtering processes that incorporate previous research findings, their results may also have been influenced by the treatment of 'not familiar' responses. The result may have been to increase the rating of less well known journals. Statistically it would be more meaningful to treat each of these responses as a zero. 
However, to do so is likely to yield a different journal rating for this reason alone, making comparison with prior research impossible.

Many studies have grouped research outlets into two or three 'tiers' (Holsapple et al. 1993). North American research has shown that when publication outlets are grouped into tiers there is some consistency in the membership of a journal to a tier. Gillenson and Stutz (1991) reported that naturally occurring 'breaks' occurred in their data to form the boundary between tiers. Although this technique may be of value in clustering publication outlets for limited samples, any boundary established by 'breaks' is an arbitrary division as ranges are continuums.

A researcher's publication history and editorial association with a journal has been observed to have little or no influence on ratings of publications (Extejt \& Smith 1990; Walstrom et al. 1995).

\section{Findings of Previous Studies}

Gillenson and Stutz (1991) and Walstrom et al. (1995) grouped the journals into three tiers. The first tier of the Gillenson \& Stutz study was made up of MIS Quarterly, Communications of the ACM and Management Science. Note that IS Research had been announced but not published at the time that data collection took place. The Walstrom et al. paper also grouped the publications into three tiers, in the first of which were MIS Quarterly, Communications of the ACM, IS Research and Management Science. In 1993, Holsapple et al. grouped journals into two tiers, the first of which contained 19 journals while the second tier had 25. Nord and Nord (1995) also grouped MIS journals into two tiers, with nine journals in the first and eight in the second.

Other studies indicate the strong performance of Communications of the ACM and MIS Quarterly at or near the top (Doke \& Luke 1987; Culnan 1987; Jackson \& Nath 1989; Koong \& Weistroffer 1989; Vogel \& Wetherbe 1984). Holsapple et al. (1993) report that there is a consensus of the top four publications in six studies.

Each discipline has a particular publication pattern in Australia. Between 1988 and 1992 the average refereed journal output per researcher for all disciplines was 3.7 papers, for physical sciences it was 8.5 and for computing and information technology (IT), 0.5 (Lowe 1995). In computing and IT, refereed conference papers are 'much more important' than refereed journal papers (Lowe 1995). As change occurs rapidly in computing the more rapid publication in conference proceedings may account for the dominance of this kind of publication. The majority of the literature attempts only to rank journals (Gillenson \& Stutz 1991; Holsapple et al.; Nord \& Nord 1995). The Walstrom et al. (1995) study considered both journals and conferences, but ranked the two types of publication outlets separately.

\section{METHODOLOGY}

\section{Epistemology, Research Question and Methods Employed}

This project is conducted within a positivist framework using both descriptive and inferential statistics. Gathering data using an interpretivist approach would have been difficult as the respondents are in different locations in Australia and elsewhere. As Australia has a small population and IS is not well established in Australian universities, the number of eminent experts on Australian IS research is restricted. As a result, the number of subjects from whom data are collected for the study is limited.

The study aimed to rank international and Australian journals and conferences appropriate as publication outlets for Australian IS researchers by perceived quality on a single scale. In this way a comparison may be made between the journals and conferences.

Distinction needs to be drawn between appropriateness and quality. Some journals may be of high quality, but due to the emphasis of Australian IS research, may be perceived to be unsuitable as a publication outlet. Respondents were required to consider the appropriateness of each journal and conference listed before rating it by quality using the criteria provided.

The major method employed in this project was an emailed survey. One disadvantage is that respondents are not anonymous. Respondents may be reluctant to declare openly their ratings for publication outlets, and in particular to indicate that they are not familiar with certain journals and conferences. This problem is a limitation of the current study.

\section{Selection of Publication Outlets}

It was necessary to develop or adopt a list of publications for inclusion in the survey instrument.

The core of journals used for analysis in this investigation was derived from a study by Walstrom et al. (1995). Walstrom's list was used as it was based in turn on previous journal studies (Doke \& Luke 1987; Gillenson \& 
Stutz 1991; Hamilton \& Ives 1982; Vogel \& Wetherbe 1984). The journals and conferences in the list derived for this study contain all those in lists of leading journals recorded by Alavi and Carlson (1992), Cheon (1993), Grover et al. (1992), Jackson and Nath (1989) and Orlikowski and Baroudi (1991). The list contains all the journals identified by Grover $e t$ al. (1993), which are consistent with the leading journals identified by Culnan (1986), Culnan and Swanson (1986), Nolan and Wetherbe (1980) and Vogel and Wetherbe (1984). All the journals in the list by Holsapple et al. (1993) appear in the list developed for this study. The journals identified as being in the first tier ranking from the study by Nord and Nord (1994) all appear in the list derived for this study, with the exception of IS Management. It is clear that there is strong support in the literature for the core of publication outlets derived for use in the current study.

In the list of journals and conferences, no distinction was made between researcher and practitioner publications. This approach echoes that taken by Walstrom et al. (1995).

There is a reliance on North American-based journals and conferences in this investigation. However, other studies of the IS literature display a similar bias (Morrison \& George 1995). Because this is an Australian study the core of North American based journals and conferences were supplemented by more regional journals and conferences. As a second method of including publication outlets seen as appropriate for Australian researchers, respondents were invited to nominate other unlisted journals and conferences and rate them. The survey instrument was developed, piloted and implemented, and required respondents to rate 38 journals and conferences. This compares with a different list of 38 journals in the Gillenson \& Stutz study (1991) and 27 publications in the Walstrom et al. (1995) study.

Three Australian journals have been added to the list developed for this study, the Australian Computer Joumal, the Australian Journal of IS and the Australian Journal of Management. The least popular five journals from those listed in the Walstrom et al. (1995) study have been omitted in order to avoid making the list unwieldy.

The five most highly ranked conferences identified in the Walstrom et al. study have been included, plus the recently introduced America's Conference on IS. The International Federation for Information Processing World Congress and IFIP Working Group TC8 Conference, as well as two conferences from the Australian region, the Pan Pacific Conference on IS and the Australasian Conference on IS have been included. The conferences and journals from the Australian region were selected for their broad appeal, and the choice was validated when no generally suggested regional publication outlets were nominated by the respondents.

The result is a list of 26 refereed journals and twelve conferences. The list from the Walstrom et al. (1995) study included only journals. As conferences and journals are both outlets for research publication, it was decided to test how researchers would rate one against the other.

\section{Survey Instrument}

The wording of the ranking instrument has been adapted from the Walstrom et al. (1995) study. A five point rating scale was used instead of the four point scale used by Walstrom, to be consistent with recommended questionnaire design techniques (Davis \& Cosenza 1988). It was considered that Walstrom et al.'s scale required respondents to rate publications according to two dimensions, one the explicit request to consider how appropriate the journal was as a publication outlet, and the other an implied request to rate the quality of the journals. The reliability of a measure is reduced by multi-dimensional questions. Accordingly, in the modified scale developed for this study only those journals and conferences considered appropriate as an outlet for Australian IS research were rated, and the scale referred only to the publication quality. In the modified measure the respondent was asked to place a cross where they were not familiar with the publication outlet. As a result, the modified measure is likely to be more reliable than the original measure where it was assumed that where a respondent did not rate a journal, the respondent was unfamiliar with the publication.

In addition to the rating instrument the questionnaire asked for the position and location of the researcher, and for a measure of the familiarity of the respondent with Australian IS research. As no publication bias was found in the rankings of publication outlets by researchers in two previous studies (Walstrom et al. 1995; Extejt \& Smith 1990), the publication history of the respondents was not investigated. The rating instrument is included in Appendix 1.

\section{Procedure and Subjects}

The questionnaire was reviewed by three experienced researchers and extensively edited before it was emailed to a pilot group of eighteen, drawn at random from a list of senior IS researchers from Australian universities. Respondents were requested to complete the questionnaire and suggest modifications. No significant modifications were generally suggested, and no changes to the survey instrument were made for the next round 
of the survey. As the survey instrument for the next round of the survey was not different to the pilot, the authority of the pilot participants was sought to use their data for this study.

The questionnaire was released to another group of 16 eminent IS researchers. This group was again drawn from senior Australian researchers, while six were from outside Australia where the researcher had an apparent interest in Australian IS research. All undertook research within, or in association with universities and were involved with at least one editorial group.

A limitation of the current study is that Australian researchers are likely to be more familiar with international IS journals and conferences than are non-Australian researchers with Australian journals and conferences. In addition, there is a possibility that some of the respondents may have been influenced by previous research that ranks journals.

\section{Analysis}

Descriptive statistics related to the appropriateness and quality of each publication were determined. To be consistent with previous recent research, when calculating the means of the ratings, the 'not familiar' and 'not appropriate' responses to publication outlets have been ignored rather than treated as a zero.

The publication outlets were then ranked from the ratings according to the respondents' perception of quality. Student's t-tests were performed on the means of the first and second ranked publication outlets, and then between the first and third, first and fourth and so on, until a significant result was obtained. The publication outlets above this point of significance were clustered to form Tier 1 . This technique was not continued to determine the boundary of further tiers as the differences between the means of the publication outlets became close and were not large enough to reach significance. Below the boundary of Tiers 1 and 2, the data were scrutinised to see whether any naturally occurring breaks existed which would could be used to divide subsequent tiers of publication outlets. A t-test was performed on the means of the journals and the means of the conferences to determine whether there was any significant difference between the two groups. A further $t$-test was conducted to compare the mean rankings of the Australian respondents with the means for the international researcher group.

\section{RESULTS AND DISCUSSION}

\section{Response}

Twelve of the 17 pilot questionnaires and 14 of the 16 questionnaires from the expert round were returned, giving a response of 26 out of 33 or $79 \%$. Twenty of the respondents held positions of (Australian) professor or associate professor, while six held other positions significant to IS. All respondents in the pilot gave authority for the data to be used for analysis. It is considered that there is little chance of error introduced into the results due to perfunctory completion of the pilot round. The respondents were senior researchers, and the excellent response rate suggests that they found the survey relevant. Each pilot respondent recorded the length of time it took to complete, which reinforced the validity of the pilot data.

\section{Ranking of Publication Outlets}

Table 1 summarises the responses for each publication outlet, presented in order of decreasing means. The column headed 'Not Appropriate Counts' indicates where a respondent considered a publication to be inappropriate for Australian IS research. The column headed 'Not Familiar Counts' indicates where a respondent placed an $x$ to register a lack of familiarity with a publication. The number of rankings $(n)$, mean, median, and standard deviation are given for each publication. The mean, median and mode or a subset of the three have been used in prior research to rank publications (Walstrom et al. 1995). The mode has not been used in this study as it may not be typical of the data, and several modes may exist (Pollard 1972).

For Table 1, the following coding scheme from the rating instrument has been used:

$1=$ Very low quality; 2 = Low Quality; $3=$ Of about average quality; $4=$ High quality;

$5=$ Very high quality. 


\begin{tabular}{|c|c|c|c|c|c|c|c|}
\hline Name of Publication Outlet & $\begin{array}{l}\text { Type of } \\
\text { Outlet }\end{array}$ & \begin{tabular}{|l|} 
Not Appropriate \\
Counts
\end{tabular} & \begin{tabular}{|l} 
Not \\
Familiar \\
Counts
\end{tabular} & \begin{tabular}{|l} 
No. of \\
Rankings \\
(n)
\end{tabular} & $\begin{array}{l}\text { Mean } \\
\text { Rating }\end{array}$ & $\begin{array}{l}\text { Median } \\
\text { Rating }\end{array}$ & Std. Dev. \\
\hline MIS Quarterly & joumal & 0 & 2 & 24 & 4.58 & 5.0 & 0.67 \\
\hline IS Research & joumal & 0 & 5 & 21 & 4.52 & 5.0 & 0.67 \\
\hline Management Science & joumal & 1 & 7 & 18 & 4.50 & 5.0 & 0.67 \\
\hline Communications of the ACM & joumal & 0 & 0 & 26 & 4.31 & 4.0 & 0.51 \\
\hline Intemational Conf on IS & conference & 0 & 2 & 24 & 4.21 & 4.0 & 0.83 \\
\hline ACM Computing Surveys & joumal & 0 & 12 & 12 & 4.17 & 4.0 & 0.79 \\
\hline IEEE Trans on Software Eng. & joumal & 4 & 1 & 21 & 4.14 & 4.0 & 0.83 \\
\hline ACM Trans on D'base Systems & joumal & 0 & 2 & 24 & 4.13 & 4.0 & 0.67 \\
\hline Harvard Business Review & joumal & 1 & 0 & 24 & 4.13 & 4.0 & 1.00 \\
\hline Sloan Management Review & joumal & 0 & 3 & 23 & 4.00 & 4.0 & 1.00 \\
\hline Academy of Management Jnl & joumal & 1 & 12 & 12 & 3.92 & 4.0 & 0.79 \\
\hline Academy of Management Rev & joumal & 1 & 12 & 12 & 3.92 & 4.0 & 0.67 \\
\hline Journal of MIS & joumal & 0 & 3 & 23 & 3.91 & 4.0 & 0.67 \\
\hline Decision Sciences & journal & 1 & 8 & 17 & 3.88 & 4.0 & 0.79 \\
\hline Joumal of Computer IS & joumal & 1 & 12 & 12 & 3.83 & 4.0 & 0.58 \\
\hline IFIP TC8 Working Conf. & conference & 0 & 1 & 24 & 3.63 & 3.5 & 0.97 \\
\hline European Jnl of IS & joumal & 1 & 5 & 20 & 3.60 & 3.5 & 0.75 \\
\hline Operations Research & joumal & 4 & 9 & 13 & 3.60 & 4.0 & 0.79 \\
\hline DATA BASE & joumal & 1 & 4 & 20 & 3.55 & 4.0 & 0.79 \\
\hline IFIP World Congress & conference & 1 & 4 & 20 & 3.55 & 3.5 & 0.83 \\
\hline Decision Support Systems & journal & 1 & 11 & 13 & 3.54 & 4.0 & 0.80 \\
\hline Information and Management & joumal & 0 & 7 & 19 & 3.42 & 3.0 & 0.90 \\
\hline Jnl of IS Management & joumal & 0 & 6 & 19 & 3.42 & 3.0 & 0.67 \\
\hline America's Conf on IS (AIS) & conference & 0 & 3 & 23 & 3.39 & 3.0 & 1.07 \\
\hline European Conf on IS & conference & 0 & 5 & 20 & 3.35 & 3.0 & 1.00 \\
\hline Hawaii Int Conf on SS (HICSS) & conference & 0 & 4 & 19 & 3.32 & 3.0 & 0.78 \\
\hline OOPSLA Conferences & conference & 3 & 12 & 10 & 3.30 & 3.0 & 0.95 \\
\hline OMEGA & joumal & 1 & 13 & 12 & 3.25 & 3.0 & 0.75 \\
\hline Australian Jnl of IS & joumal & 2 & 3 & 21 & 3.14 & 3.0 & 0.83 \\
\hline Jnl of Systems Management & joumal & 1 & 10 & 15 & 3.13 & 3.0 & 1.00 \\
\hline Australasian Conf on IS (ACIS) & conference & 2 & 1 & 23 & 3.09 & 3.0 & 1.14 \\
\hline Australian Computer Journal & journal & 2 & 1 & 23 & 3.00 & 3.0 & 0.74 \\
\hline Australian Jnl of Management & journal & 2 & 13 & 10 & 3.00 & 3.0 & 0.82 \\
\hline Decision Sci Inst Conf (DSI) & conference & 1 & 12 & 11 & 3.00 & 3.0 & 0.63 \\
\hline Interfaces (ORSA/TIMS) & journal & 0 & 11 & 15 & 3.00 & 3.0 & 0.60 \\
\hline Pan Pacific Conf on IS (PACIS) & conference & 0 & 3 & 23 & 3.00 & 3.0 & 0.79 \\
\hline Decision Suppt. S. Conf (DSS) & conference & 1 & 12 & 11 & 2.82 & 3.0 & 1.17 \\
\hline INFORMS (ORSAVTIMS) Conf. & conference & 4 & 9 & 13 & 2.50 & 2.5 & 1.00 \\
\hline
\end{tabular}

\section{Table 1 Summary of Responses for Each Publication Outlet, in Order of Decreasing Means}

The majority of the publication outlets were considered appropriate as outlets for Australian research, with the highest 'not appropriate count' of four being for specialised publication outlets such as the IEEE Transactions on Software Engineering and Operations Research. Researcher familiarity varied considerably for the publication outlets, as did the standard deviation. Communications of the ACM and Harvard Business Review were the only publications with which every respondent was familiar. The Australian Journal of Management and $O M E G A$ were the least familiar publication outlets with half of the respondents (13) indicating that the journals were unfamiliar to them. Twelve respondents or almost half of those surveyed indicated that they were not familiar with ACM Computing Surveys, the Academy of Management Journal, Journal of Computer IS, OOPSLA Conferences, Decision Science Institute Conference and Decision Support Systems Conference. Among the least familiar of the journals and conferences were some of the most specialised.

However, the first three ranked journals each had a low standard deviation with very similar means, possibly indicating agreement on the quality of the journals. The standard deviations of other publication outlets varied considerably. A high standard deviation may suggest a lack of agreement regarding quality.

The two practitioner publications, Harvard Business Review and Sloan Management Review both had high standard deviations, possibly indicating confusion regarding the role of practitioner journals for researchers. In Walstrom et al.'s (1995) study, a similar inconsistency was found as the same practitioner journals had high standard deviations. Other publication outlets with a high standard deviation included the general IS 
conferences, America's Conference on IS and the European Conference on IS. This result may indicate a lack of agreement regarding the role and quality of general IS conferences, both local and international. Some respondents rated the general IS conferences high, while other ranked them low.

Although the Walstrom et al. (1995) study ranked conferences, it did not rank conferences against journals. The ranking of the conferences from the results of this study is similar to that indicated by Walstrom et al. (1995), and there is agreement that the best quality conference is the International Conference on IS. After the International Conference on IS, Walstrom et al. ranks in order Decision Science Institute, the Hawaii International Conference on Systems Science, Decision Support Systems and INFORMS (formerly ORSA/TIMS). Apart from those in the second and third positions where the order has been transposed, the conferences ranked in the current study appear in the order proposed by Walstrom et al. However, other conferences appear in the ranking of conferences from the current study, including one recently introduced conference and three from outside North America.

\section{Other Publication Outlets}

Survey respondents were asked to suggest other noteworthy journals or conferences and rate their quality. Five journals were rated at least three times, while many others received one rating each. The IS Journal was rated ten times, the Journal of Strategic IS was rated highly by nine respondents and the Journal of Information Technology and ACM Transactions on IS were each rated three times. The most frequently mentioned journal, the IS Journal was suggested as frequently as the least well rated publication outlet from the list in Table 1 ( $n$ $=10$ ). However, it is not valid to compare the two sets of results. Recalling an item is more difficult than that of recognising and selecting an item (Preece et al. 1993). For this reason the ranking of the journals suggested by the respondents cannot be compared with the other rankings.

However, it is evident that the IS Journal and the Journal of Strategic IS should have appeared on the list presented to the respondents, although this was not obvious from the pilot. The IS Journal was first published as the Journal of IS in 1990 and was ranked poorly by Holsapple et al. (1993) from data gathered earlier. The Journal of Strategic IS was first published in 1991, but did not appear in the lists of publications put to respondents in Walstrom et al. (1995), and other prior studies. It is suggested that both journals are likely to be well considered.

\section{Ranking Position and Tiers}

The means of the rankings have been used for an initial differentiation between the publications, as they largely correspond with the median, but allow better discrimination. However, as differentiation of ranked publications on the basis of very small differences in the means may not be reliable the publications have been grouped into tiers.

Student's t-tests were performed to compare the subjects' ranking of the first ranked journal, MIS Quarterly, and the second ranked journal, IS Research, and then again between the first and the third, and the first and the fourth ranked publication outlet and so on, until a significant difference was found. Non-significant results were obtained for the first five comparisons $(p=0.186,0.135,0.103,0.088$ and 0.119$)$, which indicate that the probability of a difference arising by chance between MIS Quarterly and each of IS Research, Management Science, Communications of the ACM, International Conference on IS and ACM Computing Surveys was high. However, when a t-test was conducted to compare the ranking of the first journal, MIS Quarterly, and the seventh publication outlet, IEEE Transactions on Software Engineering, a significant result of $p=0.008$ was obtained. The result indicates that the respondents perceive a significant difference in quality between the first six publication outlets and the seventh and subsequent outlets. Accordingly, the first six publication outlets listed above have been clustered to form Tier One.

From the seventh publication outlet (the start of Tier Two) the means of the publication outlets were close, making it unlikely that the differences in the means were large enough to be significant. As a result, and despite the inconsistency, a different method was needed to differentiate between tiers subsequent to Tier One. Below the boundary between Tiers One and Two the data were scrutinised to see whether any naturally occurring breaks existed which would divide subsequent tiers of publication outlets. After Tier One, the next nine ranked publication outlets, IEEE Transactions on Software Engineering, ACM Transactions on Database Systems, Harvard Business Review, Sloan Management Review, Academy of Management Journal, Academy of Management Review, Journal of Management IS, Decision Sciences and Journal of Computer IS form a second tier, with a break in the means after the last journal (3.83 to 3.63). The last 23 publication outlets have been clustered into a third tier. 
Membership of a publication outlet to a tier is a more reliable measure of its quality than use of a specific ranked position, due to the restricted number of respondents in the study. However, when a publication outlet is located at or near the margin of a tier, the membership of the outlet to that tier is not as reliable as when a publication outlet is located more centrally within a tier.

It can be seen that the top ranked conference, International Conference on IS is placed in the first tier. This ranking supports Couger's claim (1985) that the International Conference on IS is the top ranked IS conference. It appears that this finding is applicable to Australian as well as to North American researchers. The other ten conferences have all been placed into the third tier, although the IFIP TC8 Conferences appear in the first position in the third tier, while the INFORMS (ORSA/TIMS) Conference ranks last. The last conference is not refereed.

\section{Comparison of Journals and Conferences}

A t-test was conducted to compare the ratings of the conferences against those of the journals and a significant result was obtained $(p=0.001)$.

It can be seen that there is a real difference in researchers' perceptions of the quality and appropriateness of IS journals and conferences for Australian research. Certainly some journals are considered the most prestigious publishing outlet for Australian IS researchers. However, one conference, International Conference on IS, was not clearly of less quality than the journals in Tier One. There is other evidence to support the importance of conferences to IS researchers. Many respondents have ranked general IS conferences highly, which has contributed to a large standard deviation for these publication outlets.

\section{Comparison of International and Australian Researchers}

A $p$ value of 0.014 was obtained when a t-test was performed to determine if there was a significant difference between the ratings of the international researchers and those of the Australian group. At the 0.05 level of significance, this represents a significant result. However, as the numbers of researchers were small, they may not be representative. The standard deviation of the mean ratings of the international group at 0.69 was higher than that of the Australian group at 0.50 . International researchers rated the publication outlets lower, but with less consistency than Australian researchers. This finding suggests that Australian and international researchers have different perspectives on the quality of the publication outlets.

\section{Comparison of Findings with North American Studies}

Comparison of the results was made with findings from four previous studies, Gillenson \& Stutz (1991), Holsapple et al. (1993) Nord and Nord (1995) and Walstrom et al. (1995). These four comparisons were the most meaningful as they were recent studies that considered journal rankings by, or for MIS academics. The Holsapple et al. (1993) and Nord and Nord (1995) studies ranked the publications into two tiers, not three which makes comparison with the current study more difficult. The first tier in the 1993 study contained 19 journals while the second held 25 . The Nord and Nord study placed nine journals in the first tier and eight in the second. All the studies ranked other journals that are not listed in the table. Table 2 compares the tier allocation with those from the four previous studies.

Despite the difficulties in comparing the five studies, it can be seen that there is considerable consistency, particularly if only the first two tiers are considered. Membership of Tier 1 is identical apart from the comparatively recent appearance of IS Research, inclusion of the International Conference on IS which has not been ranked against journals previously and $A C M$ Computing Surveys which appeared in the second tier in three of the four comparison studies. If allowance is made for the two tiers in the 1993 and the Nord and Nord study with the resulting larger number of publications in the first tier, there is a remarkable degree of consistency between the second tiers of the current study and the others. However, it is more difficult to compare the third tier publication outlets in the five studies as different journals were used, and the current study is the only one of the five to rank journals and conferences together.

\section{STUDY LIMITATIONS; RECOMMENDATIONS FOR FUTURE RESEARCH}

A larger survey will overcome the limitations of the small number of respondents and check any impact of nonanonymity of the subjects on the data due to the email data collection method. Future research will need to include the IS Journal and the Journal of Strategic IS. Further investigation is needed to examine the cause of the researchers' disagreement regarding the role of general IS conferences, and to discover how well 
conferences and journals rank in other fields. It may be that in fields where conference publications are considered less highly, no conferences appear in a ranking of the first 38 publication outlets.

Some cautions need to be stated. Many of the journals and conferences have different aims and each probably fulfils its goals. Exposure to similar North American ranking exercises may have influenced the respondents in their ratings. One limitation of relevant research is that non Australian researchers are likely to be less familiar with the Australian publication outlets than are Australian researchers with non-Australian journals and conferences.

\section{CONCLUSIONS}

A ranking order of journals and conferences as determined by leading Australian IS researchers was produced in this study, but more reliable is an allocation of publication outlets to three tiers.

Australian senior IS researchers considered the study to be relevant. The ordering of journals and conferences in tiers one and two is consistent with those of prior research, and the prior rankings of journals and conferences were found to be applicable to Australian IS researchers. Australian perception of IS publication outlets does not appear to be unique. However, prior research does not rank non-North American publication outlets, and the quality of Australian journals and conferences clearly is of interest to Australian IS researchers.

Australian journals and conferences, and other local conferences were not ranked highly. In general international researchers rated publication outlets lower than did Australian researchers. 'Colonial cringe' may contribute to a higher rating of international IS publication outlets and the lower rating of local outlets by Australian researchers.

The two highest ranked publication outlets were North American general IS journals. Also included in the first tier were two ACM publications, a management science journal and a general international conference on IS. The lowest ranked outlets were other conferences. The journals and conferences considered to be the least appropriate and familiar as outlets for Australian IS research were specialised rather than of general appeal. Both the researcher's familiarity and the level of agreement of the researchers varied considerably with the publication outlet.

There was widespread agreement from the researchers on the top ranked publication outlets in Tier One. While practitioner journals rated well, there was greater variation in how they were rated. The rankings of general IS conferences suffered because of a marked inconsistency in the ratings by researchers.

Australian IS researchers perceived one conference to be appropriate and of similar quality to top ranked journals as a publication outlet. This and other indications provide evidence that it is possible for IS conference publication outlets to be at least as significant to IS researchers as refereed journals. The findings of this study, particularly the last, contribute to a greater understanding of the nature of IS research and help legitimise its publication patterns which will in turn assist to validate its academic performance. These steps are necessary before IS research in Australia will gain a higher political profile and greater access to resources

\section{ACKNOWLEDGEMENTS}

I would like to thank James Alexander of the Department of Psychology, University of Tasmania and Dr Pauline O'Connor of the Department of Computer Science, James Cook University for their helpful advice regarding statistical analysis of the data. I am also indebted to Dr Chris Keen, Associate Professor Glenn Lowry and other members of the Department of Information Systems, University of Tasmania for their valuable suggestions on an early draft. 


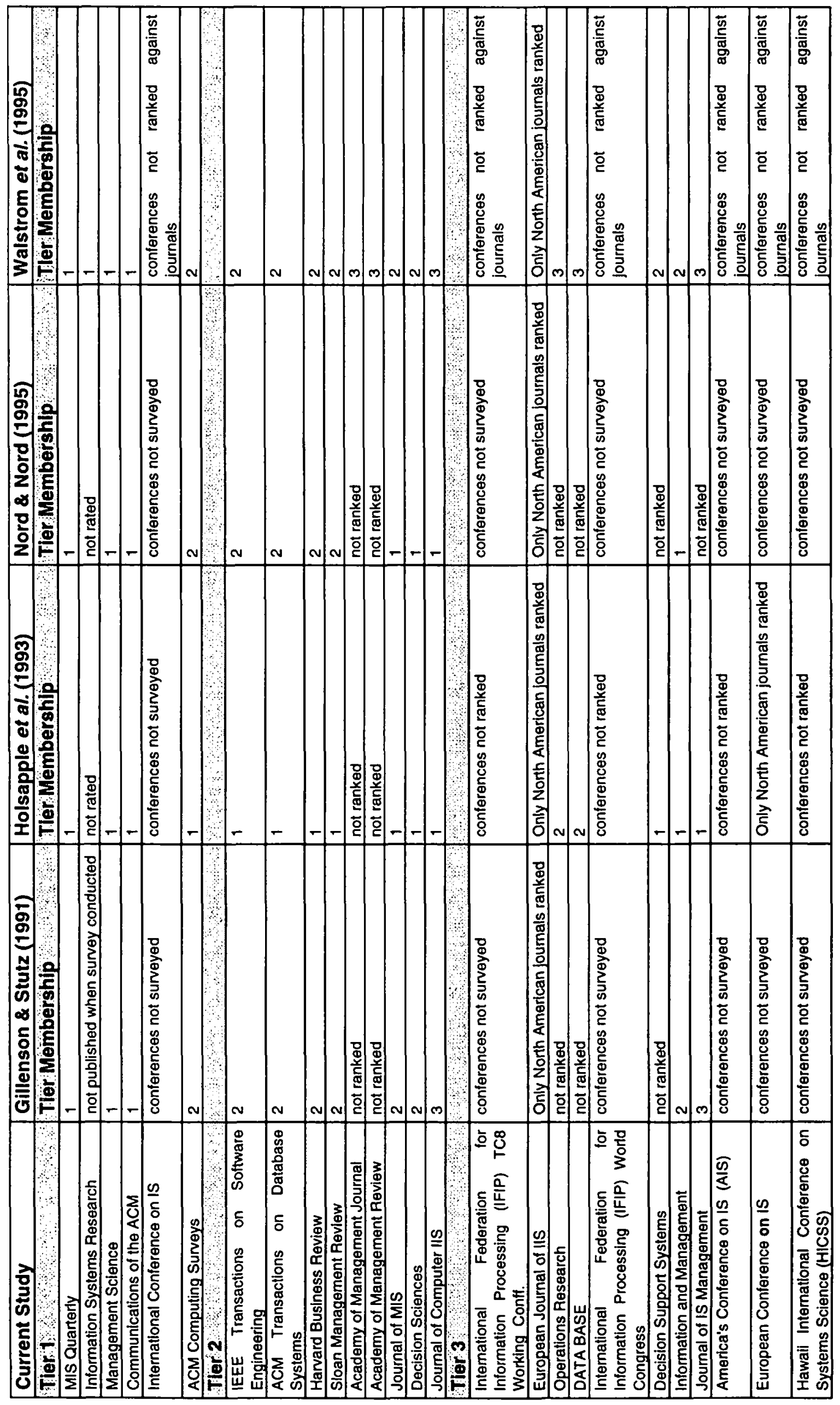




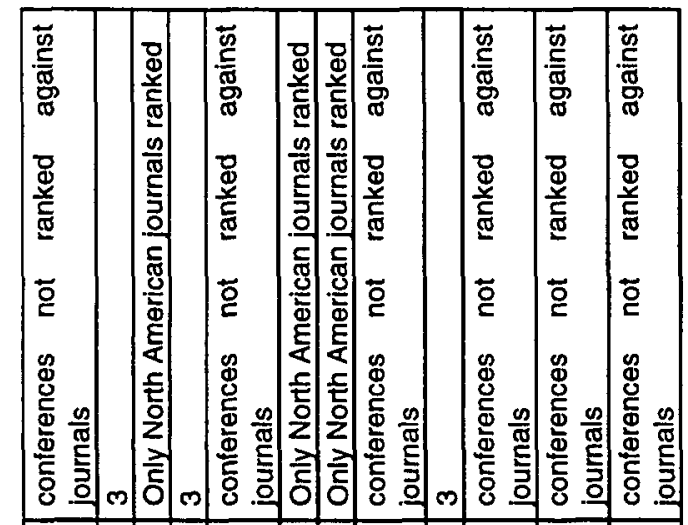

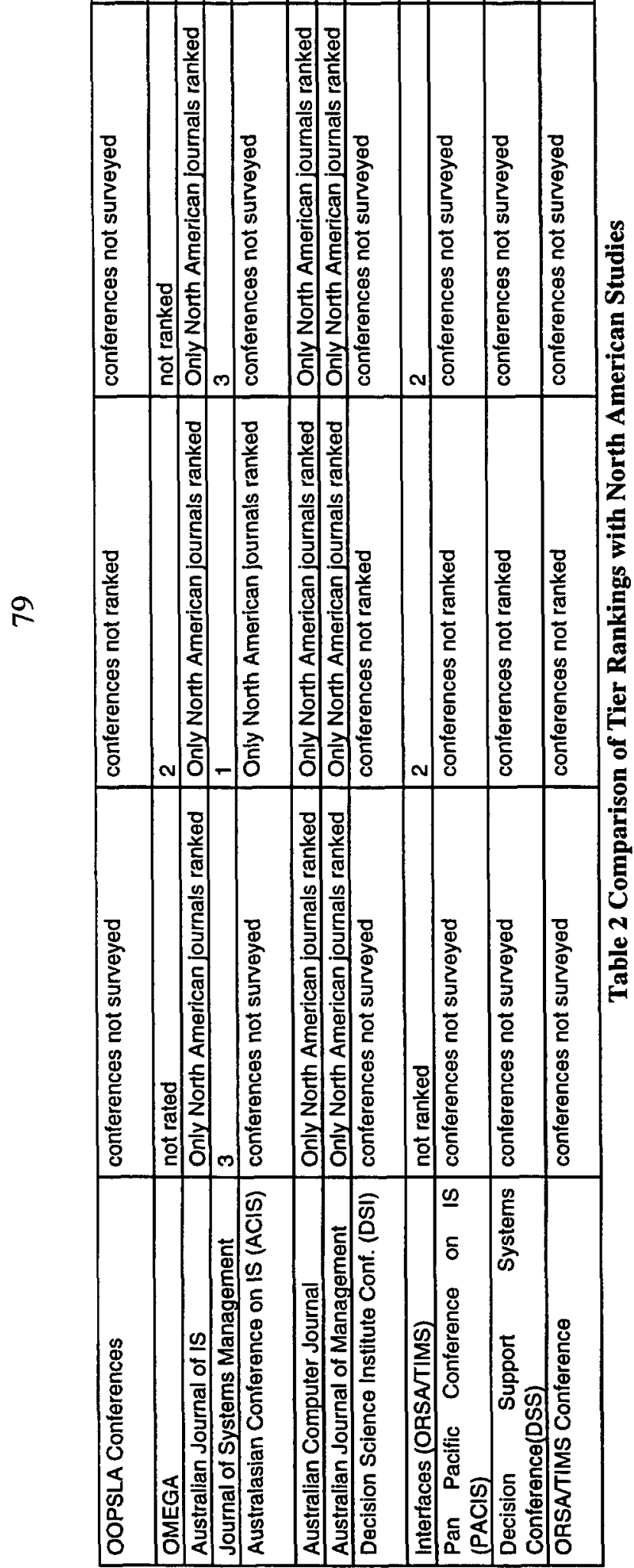




\section{REFERENCES}

Alavi, M. \& Carlson, P. (1992) “A Review of MIS Research and Disciplinary Development”, Journal of Management Information Systems, Vol 8, No 4, pp 45-62.

Amot, D. (1996, Aug 15) “Discipline Research Strategy for IT", IS-Depts [Online], Available: is-depts@fitqutedu.au. Australian Research Council (1995) Report on Research Funding Programs 1995 Volume 2 Grants and Fellowships Awarded, Department of Employment, Education and Training.

Bennetr, J. M., Broomham, R. Murton, P. M., Pearcey, T. \& Rutledge. (eds) (1994) Computing in Australia, Sydney: Hale \& Iremonger Pry Limited for Australian Computer Society Inc.

Cheon, M. J., Grover, V. \& Sabherwal, R (1993) "The Evolution of Empirical Research in IS: A study in IS maturity", Information \& Management, Vol 24, pp 107-119.

Culan, M. (1986) "The Intellectual Structure of Management Information Systems, 1972-1982: A co-citation analysis", Management Science, Vol 32, No 2, pp 156-172.

Culnan, M. J. \& Swanson, E. B. (1986) "Research in Management Information Systems, 1980-1984: Points of work and reference", MIS Quarterty, Vol 10, No 3, pp 289-301.

Davis, D. and Cosenza, R. M. (1988) Business Reseanch for Decision Making, 2nd edn., Boston: PWS-Kent Pub. Co.

Doke, E. R \& Luke, R. H. (1987) "Perceived Quality of CIS/MIS Journals among Faculty: Publishing Hierarchies", Journal of Computer Information Systems, Vol 28, No 4, pp 30-33.

Farhoomand, Ali F. (1992) "Scientific Progress of Management Information Systems", in Information Systems Reseanch: Issues, Methods and Practical Guidelines, (ed) Robert Galliers, Oxford: Blackwell Scientific Publications.

Galliers, R. (1992) Preface in Information Systems Research: Issues, methods and practical guidelines, ed Galliers, R, Oxford: Blackwell.

Gillenson, M. L. \& Stutz, J. D.(1991) “Academic Issues in MIS: Journals and books" MIS Quarterty, Vol 15, No 4, pp 447452.

Grover, V. Cheon, M. and Sabherwal, R. (1993) "The Evolution of Empirical Research in IS: A study in IS manurity" Information and Management, $\mathrm{Vol}$ 24, No 5, pp 107-119.

Grover, V., Segars, A. H\& Simon, S. (1992) “An Assessment of Institutional Research Productivity in MIS” DATA BASE, Vol 23, No 4, pp 5-8.

Hamilton, S. \& Ives, B. (1982) "MIS Research Strategies", Information and Management, Vol 5, No 6, pp 339-347.

Hamilton, S. \& Ives, B. (1983) "The Journal Communication System for MIS Research", DATA BASE, Vol 14, No 2, pp 314.

Holsapple, C., Johnson, L., Manakyan, H. \& Tanner, J. (1993) “A Citation Analysis of Business Computing Research Journals", Information and Management, Vol 25, No 5, pp 231-244.

Jackson, W. M. \& Nath, R. (1989) "Publication Patterns of MIS Researchers", Interface, Vol 11, No 2, pp 15-220.

Keen, C.D. (1995) Australasian Information Systems Survey 1995, Hobart: Department of Computer Science, University of Tasmania.

Keen, P. (1991) "Relevance and Rigor in Information Systems Research: Improving quality, confidence, cohesion and impact" in Information Systems Research: Contemporary approaches and emergent traditions, eds $\mathrm{HE}$. Nissen, $\mathrm{K}$ Heinz \& R. Hirschheim, Amsterdam: North-Holland.

King, J. L. (1993) "Editorial notes", Information Systems Research, Vol 4, No 4, pp 291-298.

Koong, K S. \& Weistroffer, H. R. (1989) "Faculty Usage of Management Information Systems Journals: A survey", Journal of Computer Information Systems, Vol 30, No 1, pp 1-4.

Lowe, I (1995) "Data Points to Research Split in So-called "Unified System", Campus Review, Mar 23-29, p 9.

Morrison, J. \& George, J. F. (1995) "Exploring the Software Engineering Component in MIS Research", Communications of the ACM, Vol 38, No 7, pp 80-91.

Nord, J. H. \& Nord, G. D. (1995) "MIS Research: Journal status assessment and analysis", Information and Management, Vol 29, No 1,pp $29-42$.

Omar, M. H. \& Goodwin, J. S. (1991) “An Investigation of Decision Support Systems Literature”, Interface, Vol 13, No 2, pp $18-23$.

Orlikowski, W. J. \& Baroudi, J. J. (1991) "Studying Information Technology in Organizations: Research approaches and assumptions", Information Systems Research, Vol 2, No 1, pp 1-28.

Pollard, A. H. (1972) Introductory Statistics, Rushcutters Bay, NSW.: Pergamon Press.

Preece, J., Benyon, D., Davies G., Keller, L. \& Rogers, Y. (1993) A Guide to Usability, Wokingham: Addison-Wesley.

Shanks, G., Rouse, A \& Amot, D. (1993) "A Review of Approaches to Research and Scholarship in Information Systems", Working Paper Series, 3/93. Department of Information Systems, Faculty of Computing and Information Technology, Monash University. 
Tsai, R., Richards, T. \& Yellen, R. (1991) "Practitioners' Issues: Perceptions of Information Systems journals and issues", Interface, Vol 13, No 3, pp 65-69.

Vogel D. R. \& Wetherbe, J. C. (1984) "MIS Research: A profile of leading journals and universities", DATA BASE, Vol 16, No 1,pp 3-14.

Walstrom, K. A., Hardgrave, B. C. \& Wilson, R. L. (1995) "Fonums for Management Information Systems Scholars", Communications of the ACM, Vol 38, No 3, pp 93-107.

\section{APPENDIX 1}

\section{Rating Instrument}

For those conferences and refereed journals that you consider to be appropriate as a publication outlet for Australian IS research, rate the following using the rating scheme given below (adapted from Walstrom, Hardgrave \& Wilson, (1995). If you consider the journal or conference to be inappropriate as a publication outlet for Australian IS research, leave its line blank.

$1=$ Very low quality

$4=$ High quality

$2=$ Low quality

$5=$ Very high quality

$3=$ Of about average quality

Mark an $\mathrm{X}$ where you are not familiar enough with the journal or conference to be able to rate it.

Academy of Management Journal

Academy of Management Review

OOPSLA conferences

ACM Computing Surveys

ACM Transactions on Database Systems

_ Operations Research

America's Conference on IS (AIS)

_ ORSA/TIMS Conference

Australian Computer Journal

Australasian Conference on IS (ACIS)

Australian Journal of Information Systems

Australian Journal of Management

Communications of the ACM

DATA BASE

Decision Sciences

Decision Science Institute Conference (DSI)

Decision Support Systems

Decision Support Systems Conference (DSS)

European Conference of Information Systems

European Journal of Information Systems

Harvard Business Review

Hawaii International Conference on Systems

Science (HICSS)

IEEE Transactions on Software Engineering

International Federation for Information

Processing (IFIP) TC8 Working

Conference

International Federation for Information

Processing (IFIP) World Congress

Information and Management

Information Systems Research

Interfaces (ORSA/TIMS)

International Conference on IS (ICIS)

Journal of Computer Information Systems

Journal of Information Systems Management

Journal of MIS

Journal of Systems Management

Management Science

MIS Quarterly

OMEGA 
If you can, suggest any additional noteworthy journals or conferences. Rate their quality using the scale given above. 